Article

\title{
Characterization, Stability Assessment, Antioxidant Evaluation and Cell Proliferation Activity of Virgin Coconut Oil-based Nanostructured Lipid Carrier Loaded with Ficus deltoidea Extract
}

\author{
Nor Azrini Nadiha Azmi ${ }^{1,2}{ }^{(0)}$, Rosnani Hasham 1,*(D), Farah Diana Ariffin ${ }^{1,3}$, \\ Amal A. M. Elgharbawy ${ }^{2}$ and Hamzah Mohd Salleh ${ }^{2}$ \\ 1 Institute of Bioproduct Development (IBD), Universiti Teknologi Malaysia, \\ Johor Bahru 81310, Johor, Malaysia; azriniazmi@gmail.com (N.A.N.A.); farahdiana.a@moh.gov.my (F.D.A.) \\ 2 International Institute of Halal Research and Training (INHART), International Islamic University Malaysia, \\ Gombak 53100, Malaysia; amalgh@iium.edu.my (A.A.M.E.); hamzah@iium.edu.my (H.M.S.) \\ 3 Institute of Medical Research (IMR), Jalan Pahang, Kuala Lumpur 50588, Malaysia \\ * Correspondence: rosnani@ibd.utm.my
}

Received: 15 September 2020; Accepted: 13 October 2020; Published: 2 November 2020

check for updates

\begin{abstract}
In this study, the Ficus deltoidea extract loaded nanostructured lipid carrier was prepared by using the melt emulsification homogenization method. Virgin coconut oil is used as liquid lipid, while glyceryl monostearate is the solid lipid. Particle size, zeta potential, entrapment efficiency, drug loading and morphology of the obtained nanostructured lipid carrier (NLC) were measured. The size of the nanostructured lipid carrier incorporated with Ficus deltoidea (FDNLC) is $158.0 \pm 1.3 \mathrm{~nm}$, with a polydispersity index of $0.15 \pm 0.02$. The zeta potential obtained is $-42.3 \pm 1.5 \mathrm{mV}$. The encapsulation efficiency and active ingredient loading capacity for FDNLC is $87.4 \% \pm 1.3 \%$ and $8.5 \% \pm 1.2 \%$, respectively. The shape of FDNLC is almost spherical and the stability assessment showed that the obtained formulation is at least stable for 40 days. When compared with the positive controls, which are Trolox and ascorbic acid, FDNLC shows the highest antioxidant value. Cell proliferation activity study indicates that FDNLC is not toxic to cells, and FDNLC could potentially treat damage by ultraviolet B (UVB) irradiation.
\end{abstract}

Keywords: nanostructured lipid carrier (NLC); Ficus deltoidea; virgin coconut oil; characterization; stability; antioxidant

\section{Introduction}

Ficus deltoidea (FD) or better known as mistletoe fig is a small plant originated from the Moraceae family. FD is a native plant of Malaysia that possesses potential for varied purposes. It had been used as a traditional remedy for many diseases, including diabetes and relieving pain. Ramamurthy (2014) reported that FD is also used for skin diseases, pneumonia, diarrhea, heart problems and migraines. The active compounds in the extract of the plant possess anticancer, anti-inflammatory, antioxidant, antinociceptive and antiphotoaging effects [1]. Haron stated that polyphenols and naringin are among the chemicals found in FD, which are beneficial for anti-inflammatory effects [2].

Due to their advantages, a variety of research was executed on the application of FD. Along with that, a study by Hasham et al. proposed that FD extract hinders the production of inflammatory cytokines and could be an effective protection tool to treat skin diseases [3]. The research concluded that FD extract might be helpful against ultraviolet B (UVB) induced skin damage and is beneficial in antiphotoaging cosmetic products. UVB rays are accountable for sunburn and skin cancers such as 
malignant melanoma. Moreover, a study by Mahmood and Khaled showed an enhancement in wound healing in rats treated with FD [4]. The results had proved the efficacy of FD extract to accelerate the rate of wound healing in the experimentally induced wounds in rats. However, the disadvantage of using plant extract is that the bioactive substances are unstable when exposed to light and could lose activity during storage [5]. It is also difficult for biologically active water-soluble extracts to permeate through human skin, which naturally has a hydrophobic attribute.

Due to the above reasons, new systems have been studied to heighten the penetration of therapeutic molecules through the skin [6]. In the early 1990s, Solid lipid nanoparticles (SLNs) were introduced to replace carrier systems such as emulsions, liposomes and polymeric nanoparticles [7]. However, some problems were associated with SLN, such as low drug loading and drug expulsion that might happen during storage [8]. A nanostructured lipid carrier system (NLC) is a new generation of SLN, which composes of a liquid lipid blended with a solid lipid to form a matrix of nanostructured solid particle. Liquid lipid in NLC is employed to change the formation of SLN. This structure intensifies the loading and incorporates the drug securely during storage. However, there is limited research on the association of lipid nanocarriers with plant medicine in the bionanotechnology field [9]. Usage of appropriate renewable vegetable sources is highly feasible to comply with both industrial and customer demands, because of the health advantages and improved delivery features it offers. Final solid lipid core should contain structural imperfections to increase the incorporation of the drugs into the system. The system has been manifested as an effective system to increase skin hydration due to its physiological lipid composition and occlusive effect properties [10]. The small size of NLCs ensures close contact with the stratum corneum and can increase the amount of the active compound penetrating the skin [11]. NLCs are novel drug delivery systems for the delivery of actives with high solubility, stability, powerful skin penetration, and low skin discomfort [12].

Virgin coconut oil (VCO) is described as the yield of oil coming from the fresh and mature kernel of the coconut (Cocos nucifera L.) through mechanical and natural means, as long as it does not result in any changes to the oil [13], whether or not using heat. Currently, VCO became very widely known for its usefulness. In 2009, Marina et al. had proven refined coconut oil has lower antioxidant activity than VCO [14]. Besides, VCO is an exceptional ingredient that could work as skin softener and moisturizer, which are very important in the cosmetics industry [15]. Kim et al. had shown that VCO contributes to protective barrier functions as the stratum corneum increased expression of cornified envelopes (CEs) components after application of the oil [16]. In this work, VCO has been chosen as the liquid lipid in the NLC system because of their advantages for the skin and the NLC system itself.

In this work, attempts to produce nanostructured lipid carrier incorporated with Ficus deltoidea (FDNLC) were done using the ultrasonication technique. The successfully obtained formulation was further characterized using several essential parameters such as particle size and polydispersity index, zeta potential, drug entrapment efficiency (EE) and transmission electron microscopy (TEM). The stability, antioxidant, skin permeation and cell proliferation activity were also assessed.

\section{Materials and Methods}

\subsection{Materials}

Distilled water, Ficus deltoidea extract, Folin-Ciocalteau reagent, gallic acid, glyceryl monostearate, virgin coconut oil, Sephadex G-50, sodium carbonate, soy lecithin, tween 80, 2,2-diphenyl-1-picrylhydrazyl (DPPH) reagent, Trolox and ascorbic acid. Fibroblast cell was utilized throughout this experiment. Fibroblast cell (HSF 1184) was cultivated in Dulbecco's modified Eagle's medium (DMEM), which contains 10\% fetal bovine serum and $1 \%$ penicillin with streptomycin. The cells were maintained at $37^{\circ} \mathrm{C}$ in a humidified atmosphere of $5 \%$ carbon dioxide $\left(\mathrm{CO}_{2}\right)$. 


\subsection{Methods}

\subsubsection{Preparation of FD Loaded Nanostructured Lipid Carrier}

Nanostructured lipid carrier incorporated with Ficus deltoidea extract (FDNLC) was prepared using a method by Rosli et al. with minor modifications [17]. The melt emulsification homogenization technique was used to prepare FDNLC. There were two phases involved in the preparation: the lipid phase and aqueous phase. In this technique, both phases were prepared separately. Lipid phase composes of solid lipid (glyceryl monostearate) and liquid lipid (virgin coconut oil). The aqueous phase consists of distilled water, surfactant (tween- 80 and soy lecithin) and also FD extract. First, soy lecithin $(6.5 \%)$ and tween-80 (7.5\%) were diluted with distilled water. The mixture was heated at $40{ }^{\circ} \mathrm{C}$ until all components were mixed well. For the lipid phase, $2 \%$ glyceryl monostearate was combined with $10 \% \mathrm{VCO}$, and the mixture was heated until it is entirely melted. After that, the aqueous phase mixture was added into the lipid phase mixture and then it was well stirred. A magnetic stirrer was used to stir both mixtures. Then, the active ingredient ( $4 \%$ FD extract) was added to the resultant mixture of the aqueous and lipid phases. Later, the final mixture was homogenized using IKA Ultra Turrax ${ }^{\circledR}$ Homogenizer at $8000 \mathrm{rpm}$ for three minutes. Finally, probe sonicator was used to ultrasonicate the obtained pre-emulsion for $20 \mathrm{~min}$ and cooled in an iced water bath for homogenous dispersion.

\subsubsection{Characterization FD Loaded Nanostructured Lipid Carrier}

\section{Measurement of Particle Size and Polydispersity Index}

The particle size determination and polydispersity index (PDI) of the FDNLC sample were analyzed by photon correlation spectroscopy using Zetasizer Nano S (Malvern Instruments, Malvern, UK). All samples were first diluted using distilled water at a ratio of 1:9 to ensure that the light scattering intensity was within the instrument's sensitivity range [18]. Each of the measurement was done in triplicate. Refractive indices for particles were 1.54, and for water was 1.33.

\section{Encapsulation Efficiency and Drug Loading}

Encapsulation efficiency (EE\%) is the estimation of the quantity of encapsulated drug per unit weight of nanoparticles. EE (\%) was calculated to determine the percentage of FDNLC using the size exclusion spin mini-column, according to Dangi and Shakya, with modifications [19]. Encapsulated NLC was separated from non-encapsulated FD extract using a spin mini-column packed with Sephadex G-50 (Sigma Aldrich, Selangor, Malaysia) according to the size exclusion concept. Before the spin mini-column was ready to be used, the spin mini-column was centrifuged $2000 \mathrm{rpm}$ for two minutes to remove excess water. After that, $0.1 \mathrm{~mL}$ of NLC dispersion was loaded into the spin mini-column without breaking the initial state of the Sephadex G-50 in the mini-column. The mini-column was centrifuged again at $2000 \mathrm{rpm}$ for $2 \mathrm{~min}$ to elute the encapsulated NLC, assuming that the NLC particles were the biggest particle in the dispersion. The eluted sample in a $1.5 \mathrm{~mL}$ centrifuge tube was then added with ethanol (1:1 ratio) to disrupt the lipid matrix of NLC and release the encapsulated FD extract. The same lipid disruption method was applied for the total amount of FD extract determination. The total amount of FD extract content in the NLC dispersion was then the sum of the encapsulated FD and the free FD extract. The validation for spin mini-column methodology was carried out by loading the FD extract solution into the spin mini-column to prove that the free FD extract was retained in the packed Sephadex G-50. The elution was collected and then, the absorbance of the elution is determined by UV spectrophotometer at $760 \mathrm{~nm}$. The experiments were performed in triplicate. The encapsulation efficiency (EE\%) is computed using Equation (1):

$$
\mathrm{EE}(\%)=\left(n_{1} / n_{2}\right) \times 100
$$

where $n_{1}=$ amount of encapsulated FD and $n_{2}=$ total amount of FD in total suspension. 
While the percentage of drug loading (DL\%) capacity is calculated using Equation (2):

$$
\mathrm{DL}(\%)=\left[\left(n_{1}-n_{2}\right) / \mathrm{T}_{\text {lipid }}\right] \times 100
$$

where $n_{1}=$ amount of encapsulated FD; $n_{2}=$ total amount of FD in full suspension and $\mathrm{T}_{\text {lipid }}=$ total weight of lipid in the formulation.

\section{Determination of Zeta Potential}

To measure the stability of the particle, the zeta potentials of the samples were measured using Zetasizer Nano Z (Malvern Instrument, Malvern, UK). The samples were diluted with distilled water before the analysis, and all measurements were performed at $25^{\circ} \mathrm{C}$. Zeta potential values of $\pm 30 \mathrm{mV}$ and above were characterized as stable formulation. Each reading was taken in triplicate. The refractive indices of particles and water used were 1.54 and 1.33, respectively.

Investigation of the Morphological Structure

The morphology of the FDNLC was observed through a transmission electron microscope (JEM 2100 TEM) as described by Noor et al. [20]. The freshly prepared sample was placed on copper grids for viewing, and excess droplets were absorbed away with filter paper. After five minutes, a drop of $2 \%$ phosphotungstic acid was placed onto the copper for staining. The grid was dried at room temperature and observed using TEM. Multiple resolutions were used to observe the NLC image, starting from 5 to $100 \mathrm{kV}$.

\subsubsection{Stability Study}

The FDNLC was stored at three different temperatures, cold $\left(4{ }^{\circ} \mathrm{C}\right)$, room $\left(25^{\circ} \mathrm{C}\right)$ and hot $\left(40{ }^{\circ} \mathrm{C}\right)$ for 40 days. The size and polydispersity index of the samples were evaluated on days $1,7,18$ and 40 .

\subsubsection{Antioxidant Activity}

To assess the antioxidant activity, 2,2-diphenyl-1-picrylhydrazyl (DPPH) assay was used, as described by Sharma and Bhat [21]. Briefly, $300 \mu \mathrm{L}$ of NLC suspension $(15.625,31.25,62.5,125$ and $250 \mu \mathrm{g} / \mathrm{mL}$ ) were mixed with $2.7 \mathrm{~mL}$ of DPPH (final concentration of DPPH was $2.0 \times 10^{-4} \mathrm{M}$ ). The mixture was vigorously shaken to ensure the samples and DPPH reagent was adequately mixed. Then, samples were incubated at room temperature for $30 \mathrm{~min}$, and the absorbance was recorded. Mean average values were taken as the experiment was performed in triplicates. Standards that were ascorbic acid and Trolox were used to compare the results obtained. The absorbance of DPPH was recorded, and $\mathrm{IC}_{50}$ was calculated using Equation (3).

$$
\mathrm{IC}_{50}=\left[\left(A_{0}-A_{e}\right) / A_{0}\right] \times 100
$$

where $A_{e}$ is the absorbance of the extracts. The antioxidant potential of all the extracts at each concentration was calculated.

\subsubsection{Skin Permeation Study}

The diffusion experiment was conducted using Franz diffusion cells as described by Noor et al. [20]. The diffusion experiment was conducted in an automatic transdermal diffusion system (Perkin Elmer, Norwalk, CT, USA). The cells consist of three vertical Franz style diffusion cells, a thermally controlled circulating water bath and magnetic stir console, providing a similar condition to human skin. An epidermis layer was installed in a specific position where the stratum corneum facing the donor cell and the dermis layer was soaked in the receptor buffered solution. The receptor and donor compartments were filled with PBS buffer ( $\mathrm{pH}$ 6.5). The diffusion cells were maintained and equilibrated at $37^{\circ} \mathrm{C}$ by the recirculating water bath, while continuous stirring of the buffer solution 
in the receptor and the donor compartment was maintained at $300 \mathrm{rpm}$ for $30 \mathrm{~min}$. After $30 \mathrm{~min}$ of equilibration, $1 \mathrm{~mL}$ of sample was added in the donor compartment. From the receptor chamber, $1 \mathrm{~mL}$ aliquot of the sample was collected at $0.5,1,1.5,2,3,4,6,8,12,16,20$ and $24 \mathrm{~h}(\mathrm{~s})$. Fresh buffer at the same amount of the collected aliquots was added to the receptor chamber to maintain a constant volume inside the chamber. The experiment was done in triplicate. The collected receptor fluid was evaluated using the total phenolic compound (TPC) assay to quantify the FD amount in the samples expressed in gallic acid equivalent (GAE) and performed in duplicate. Permeated cumulative amount of active ingredients was calculated based on the measured FD amount in GAE of the collected receptor fluid obtained from the TPC assay in each diffusion cell and was plotted as a function of time. From the plotted graph, the slope and the $\mathrm{x}$-intercept (lag times, $\mathrm{tL}$ ) were determined to obtain the steady-state flux (Jss) using the linear regression analysis, following Fick's first law. Collected samples from in vitro skin permeation study were quantified using the total phenolic content assay representing the amount of FD extract permeated through the skin. This method was referred from Almey et al. [22]. The quantified FD extract was expressed in gallic acid equivalent (GAE) unit. Of sample $0.1 \mathrm{~mL}$ was added to $0.75 \mathrm{~mL}$ of 10 -fold dilution of Folin-Ciocalteu reagent with vigorous mixing and was rested for $5 \mathrm{~min}$. Then, $0.75 \mathrm{~mL}$ of $6 \%(w / v)$ sodium carbonate was added to the solution. The samples were incubated for $90 \mathrm{~min}$ at room temperature before the absorbance reading was taken at $725 \mathrm{~nm}$ with the UV spectrophotometer. The measurement was performed in triplicate.

\subsubsection{Cell Proliferative Study}

MTT assay was used to estimate cell viability and proliferation. First, fibroblast cells were seed at a density of $1 \times 10^{4}$ cells using a 96 well plate. Then, after it reached $100 \%$ confluent in culture media, the fibroblast cells were treated with several different concentrations of FDNLC for $24 \mathrm{~h}$. The media was removed and washed with PBS. The cells were incubated in the dark with $20 \mu \mathrm{L}$ of $5 \mathrm{mg} / \mathrm{mL} \mathrm{MTT}$ solution for $4 \mathrm{~h}$ at $37^{\circ} \mathrm{C}$. A volume of $100 \mu \mathrm{L}$ of dimethyl sulfoxide (DMSO) was added to each well. The absorbance was measured at $570 \mathrm{~nm}$ using TECAN M200 Pro Multiplate reader. The percentage of the viable cells was calculated by defining the cell viability without treatment as $100 \%$.

\section{Results and Discussions}

\subsection{Physicochemical Properties}

The FDNLC dispersions were yellowish-white in color, odorless and liquid in nature, which can be seen in Figure 1. It was stable and did not show any sedimentation even after centrifugation at $5000 \mathrm{rpm}$ for $30 \mathrm{~min}$. The blank dispersions of NLC were also prepared. The blank had the same components as FDNLC except for the amount of FD was replaced with water. The characteristics were similar to FDNLC, but the color was whiter as it did not contain FD extract. 


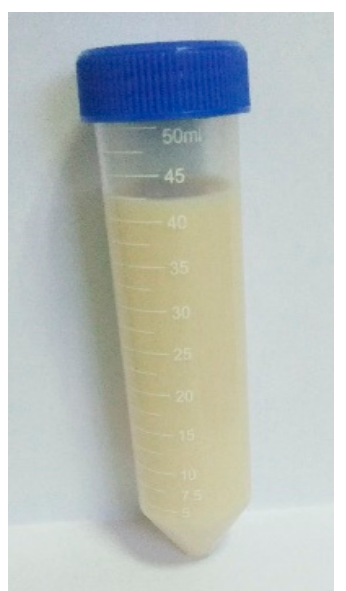

(a)

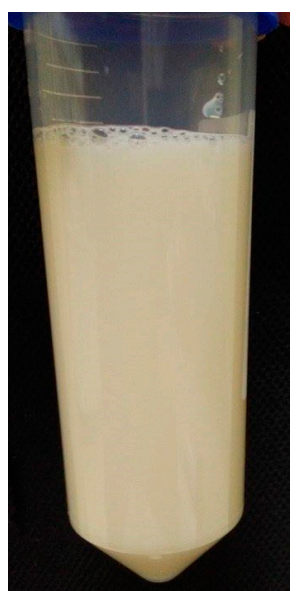

(b)

Figure 1. (a) Nanostructured lipid carrier incorporated with Ficus deltoidea (FDNLC) and (b) blank dispersions of nanostructured lipid carrier (without Ficus deltoidea).

\subsection{Characterization of Ficus deltoidea Loaded Nanostructured Lipid Carrier}

\subsubsection{Particle Size and PDI of Ficus deltoidea Loaded Nanostructured Lipid Carrier}

Initially, blank NLC dispersion and FDNLC were prepared and characterized. The most important characteristic of an NLC formulation is the particle size. This is because the small size of nanoparticles ensures close contact of the extract with the stratum corneum and eventually makes it easier for the extract to penetrate the skin. Based on Table 1, the sizes are $153.1 \pm 2.5 \mathrm{~nm}$ and $158.0 \pm 1.3 \mathrm{~nm}$ for blank NLC and FDNLC, respectively. The formulation for FDNLC achieved an appropriate size for the topical route, which is less than $500 \mathrm{~nm}$. The small size of NLC gives a large surface area of the system and low interfacial tension of the droplets, thus enables easy penetration through the skin [23]. The particle size of lipid nanoparticles is affected by various parameters, such as the composition of the formulation and production methods. In this study, the small particle size might be owing to the surfactant mixture, other than accurate production methods and experimental conditions. Using a blend of emulsifiers can stabilize the emulsion in terms of the coalescence rate. When the amount of surfactant increased, the particle size decreased with a monodispersed size distribution. This happened because increasing the surfactant concentration lowered the surface tension and stabilized newly developed surfaces during homogenization and produce smaller particles [24]. At decreased concentrations of surfactant, aggregation accelerated where the coated fraction of particle surface area remained small. This is observed in a similar study by Zirak and Pezeshki, which shows with a higher concentration of surfactant, the particle size is smaller [24]. The amount of active ingredient, which is FD, impacts the particle size and PDI of FDNLC. As shown in Figure 2, the size and PDI increase steadily when the amount of FD increased in the formulation. A similar trend is observed in a study by Das et al. [25]. The results portrayed particle size increases when active ingredient concentration increases. Huge augmentation of particle size and PDI must be due to the presence of a large number of unencapsulated drug molecules.

Table 1. Comparison of particle size and polydispersity index (PDI) between FDNLC and the blank. Each value represents the mean $\pm \mathrm{SD}(n=3)$.

\begin{tabular}{ccc}
\hline & Blank & FDNLC \\
\hline Size (nm) & $153.1 \pm 2.5$ & $158.0 \pm 1.3$ \\
PDI & $0.19 \pm 0.01^{*}$ & $0.15 \pm 0.02$ \\
\hline compared to FDNLC, indicate as a statistically significant value.
\end{tabular}




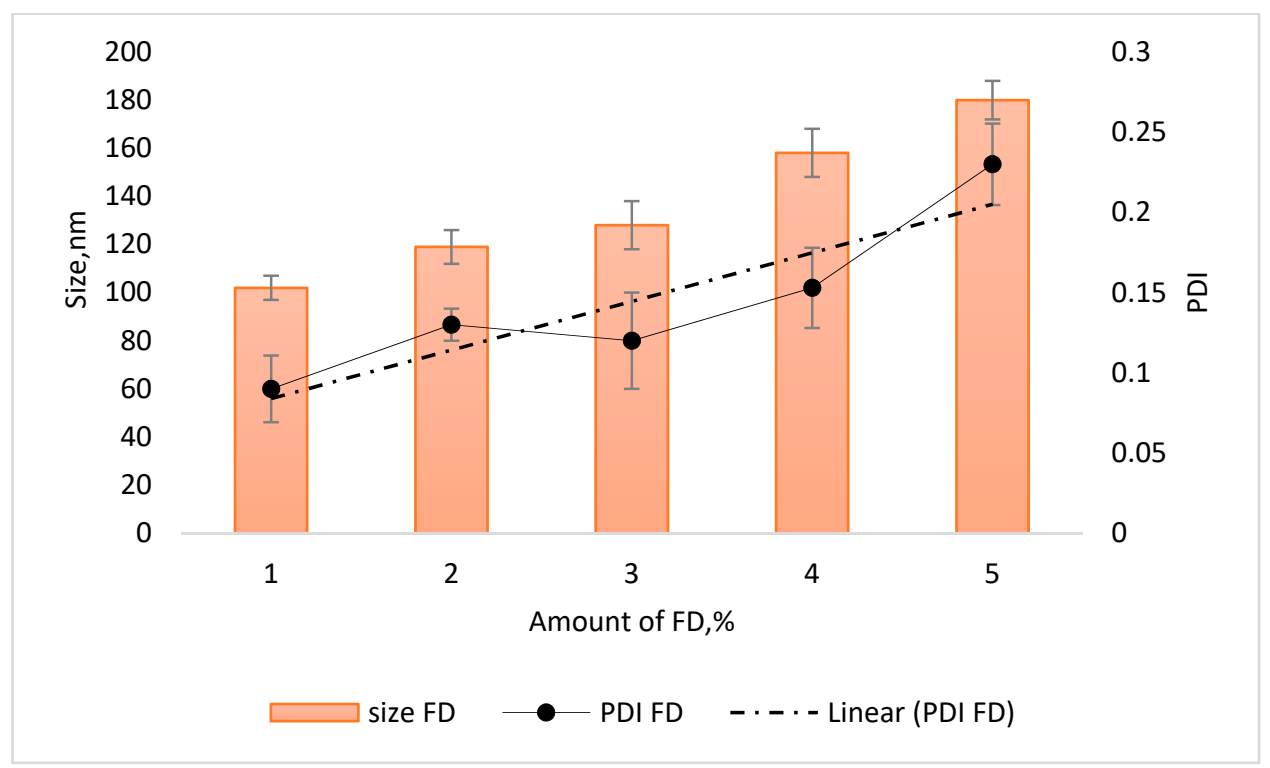

Figure 2. Effect of the composition of active (FD) on size and PDI of FDNLC. Experiments were done in triplicate $(n=3)$.

Size, however, rarely presented as a single value but rather a representative value of a distribution that can be narrow, moderate or broad. As can be seen in the PDI value in Table 1, there was no significant difference between the blank and FDNLC. Both readings were below 0.2 and indicate homogeneity of the formulations. This might be due to the sufficient power of the probe sonicator and the time taken to homogenize the formulations. The presence of high surfactant concentrations might also contribute to the small PDI value. High tween 80 and soy lecithin concentrations allow ease of dispersion, reduced aggregation and hence a reduction in PDI. As reported by Mitri et al. in 2011, the polydispersity parameter provides important indications concerning sample homogeneity, as values below 0.25 reflect relatively homogeneous nanoparticles, with a minimum predisposition to aggregation [26].

\subsubsection{Zeta Potential of FD Loaded Nanostructured Lipid Carrier}

Zeta potential is an important parameter that predicts the physical stability of colloidal dispersions. In theory, a higher value of zeta potential, either positive or negative, tended to stabilize the suspension. Aggregation phenomena are less likely to occur for charged particles with pronounced zeta potential $(>|30| \mathrm{mV})$ due to the electrostatic repulsion between particles with the same electrical charge [27]. In this study, both blank and FDNLC dispersions possessed zeta potential value higher than $30 \mathrm{mV}$, which were $-42.6 \pm 1.7 \mathrm{mV}$ for the blank and $-42.3 \pm 1.5 \mathrm{mV}$ for FDNLC. This strongly suggests a good physical stability for the formulations. It is also a sign of good skin permeation ability and long-term durability, which is supported by the stability testing in Section 3.3. Overall, the formulations exhibit a good physical stability, which might be attributed to the role of surfactant.

\subsubsection{Active Ingredient Loading and Encapsulation Efficiency of FD Loaded Nanostructured} Lipid Carrier

Active ingredient loading and encapsulation efficiency were determined by measuring the amount of encapsulated active ingredient within the nanoparticles [25]. The encapsulation efficiency and active ingredient loading capacity for FDNLC was $87.4 \% \pm 1.3 \%$ and $8.5 \% \pm 1.2 \%$, respectively. The active ingredient loading capacity was $\leq 10 \%$, which is higher than a study by Jia et al. [28], which use silybin as the drug, but lower than Chu et al. [29] work, which incorporated polymer in their study. 
The low value of drug loading might be due to the hydrophilic character of the FD. However, the drug loading capacity was not very small because the presence of biocompatible surfactants in NLC formulation facilitated the encapsulation of FD extract in FDNLC. The encapsulation efficiency was relatively high as the amount of FD added was adequate for the encapsulation capacity of the amount of lipid used (low drug to lipid ratio). It was reported by Jenning et al. that the incorporation of liquid lipid to solid lipid can lead to massive crystal order disturbance, and the resulting matrix of lipid particles indicates great imperfections in the crystal lattice and leaves enough space to accommodate drug molecules, thus leading to improved drug entrapment efficiency and drug loading capacity [30]. High encapsulation efficiency of the formulation is beneficial to reduce the skin irritation of drug due to avoidance of direct contact between active ingredient and skin surface.

\subsubsection{Investigation of Morphological Structure}

Information on the morphology and size of the particles were obtained through TEM. TEM is actually similar to a normal microscope, but TEM used electrons instead of photons, which produce better magnification and a clearer image. This is because electron wavelengths are smaller than light wavelengths. Based on Figure 3, the FDNLC had a spherical shape with smooth surfaces, which is agreeable with some other studies. In addition, the image also had confirmed the nano size of FDNLC, which supports the results of particle size measurement by Zetasizer in Section 3.3. The uniformity of the particle size also supports the narrow particle size distribution. Furthermore, Figure 3 depicts that all particles were almost similar in size in each system and did not aggregate, which indicates that all the systems were monodispersed.

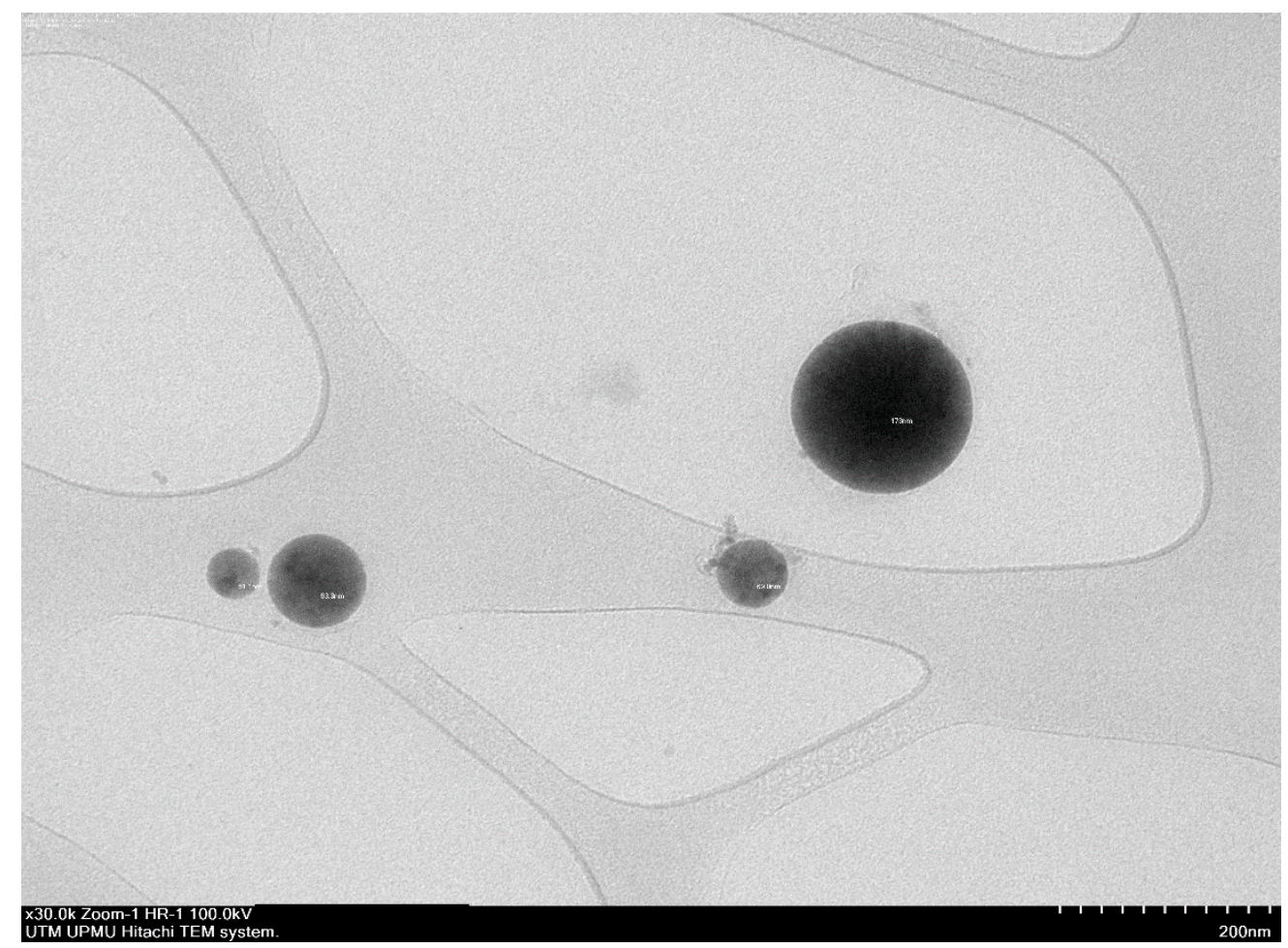

Figure 3. The morphology of the nanostructured lipid carrier (NLC) incorporated with FD (FDNLC) from TEM. Magnification $\times 30,100.0 \mathrm{kV}$.

\subsection{Stability of FD Loaded Nanostructured Lipid Carrier}

Stability tests are important in helping to predict the shelf life of the product. The data obtained indicate a constant value of particle size and PDI after 40 days. No flocculation, aggregation, gelation and 
color change were observed in the samples during the storage. In Figure 4, only a slight increase in particle size was observed when the sample was stored at $40{ }^{\circ} \mathrm{C}$. At room temperature, there was a negligible decreasing trend in particle size. While at $4{ }^{\circ} \mathrm{C}$, the particle size decreased from $158.0 \pm 1.2$ to $130.9 \pm 1.5 \mathrm{~nm}$. However, even after storage of 40 days, the sample stayed as nano size. The polydispersity index (PDI) was used as a measure of broadness of molecular weight distribution. For the PDI value, it can be seen in Figure 5, that all the samples showed an increasing trend. However, even at day 40, the PDI value remained below 0.200. This shows a narrow particle distribution of the samples. These results were in agreement with the zeta potential results. Venkateswarlu and Manjunath disclosed that good stability might be derived from the small particle size, the slow transition of lipid and the steric effect of tween 80 [31]. The particle size stability might be attributed to the type of liquid lipid and solid lipid. Glycerol monostearate is the ester of fatty acids and glycerol, which contain an aliphatic lipophilic chain contributed by fatty acyl group and two hydroxyl groups form the hydrophilic part contributed by glycerol. Due to the amphiphilic nature, monoglycerides are capable of stabilizing emulsions. The amphiphilic nature of glycerol monostearate might affect its chemical reaction with the liquid lipid, and the hydrophilic FD extract, which would stabilize NLC dispersion. The concentration of the surfactant also plays an important role in the stabilization of the lipid particles of NLCs. From the concentration aspect, Huang et al. [32] demonstrated that colloidal nanoparticles have large surface areas. When the amount of surfactant is not enough, there will be lipid particles in NLCs being uncovered by the surfactant, leading to flocculation, aggregation and gelation. From the stability results, it can be concluded that the amounts of tween-80 and soy lecithin were adequate to stabilize the FDNLC. Apart from that, the blend of surfactants played an important role in stabilizing the formulations.

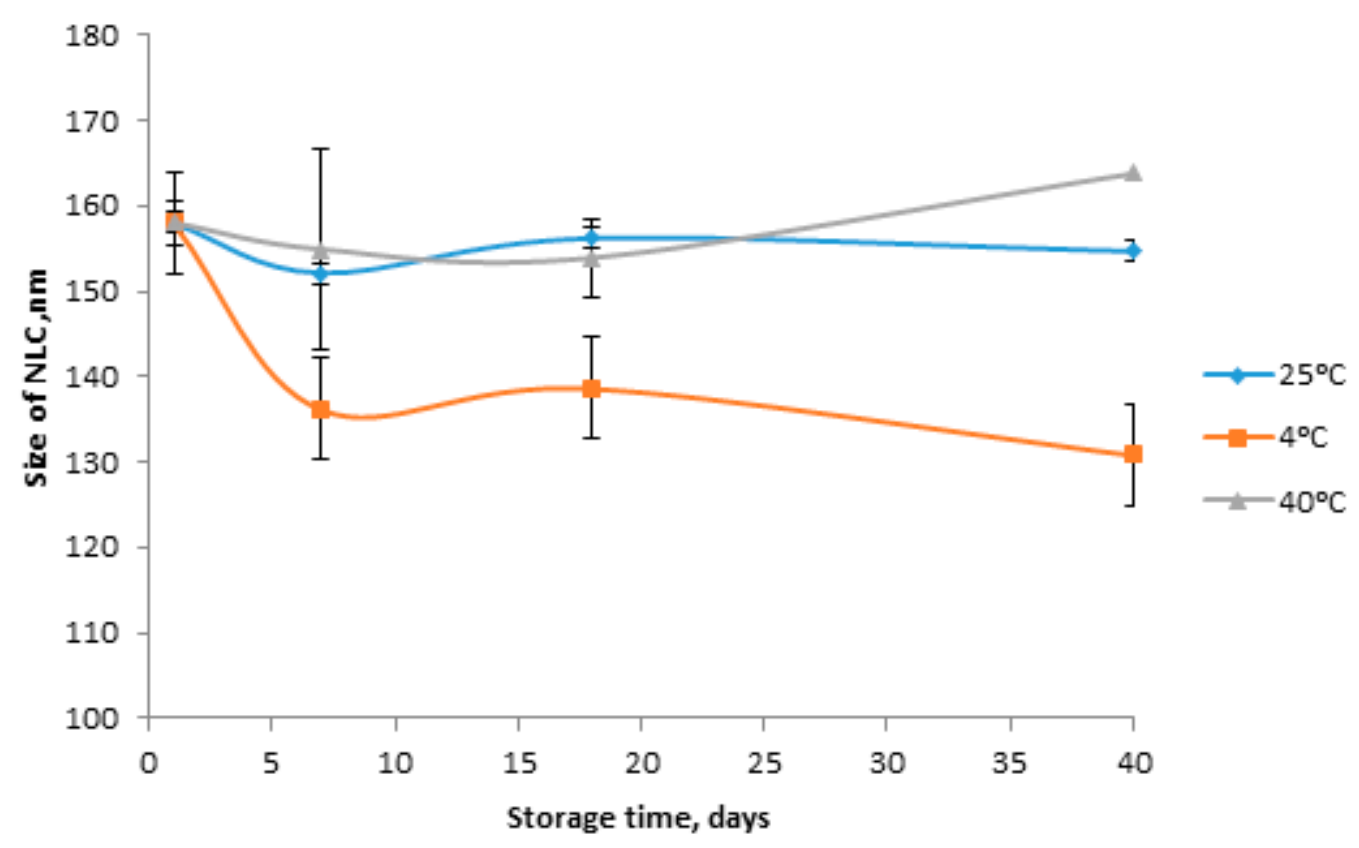

Figure 4. Changes of FDNLC particle size during storage at $4{ }^{\circ} \mathrm{C}, 25^{\circ} \mathrm{C}$ and $40{ }^{\circ} \mathrm{C}$ throughout 40 days of study. Experiments were done in triplicate $(n=3)$. 


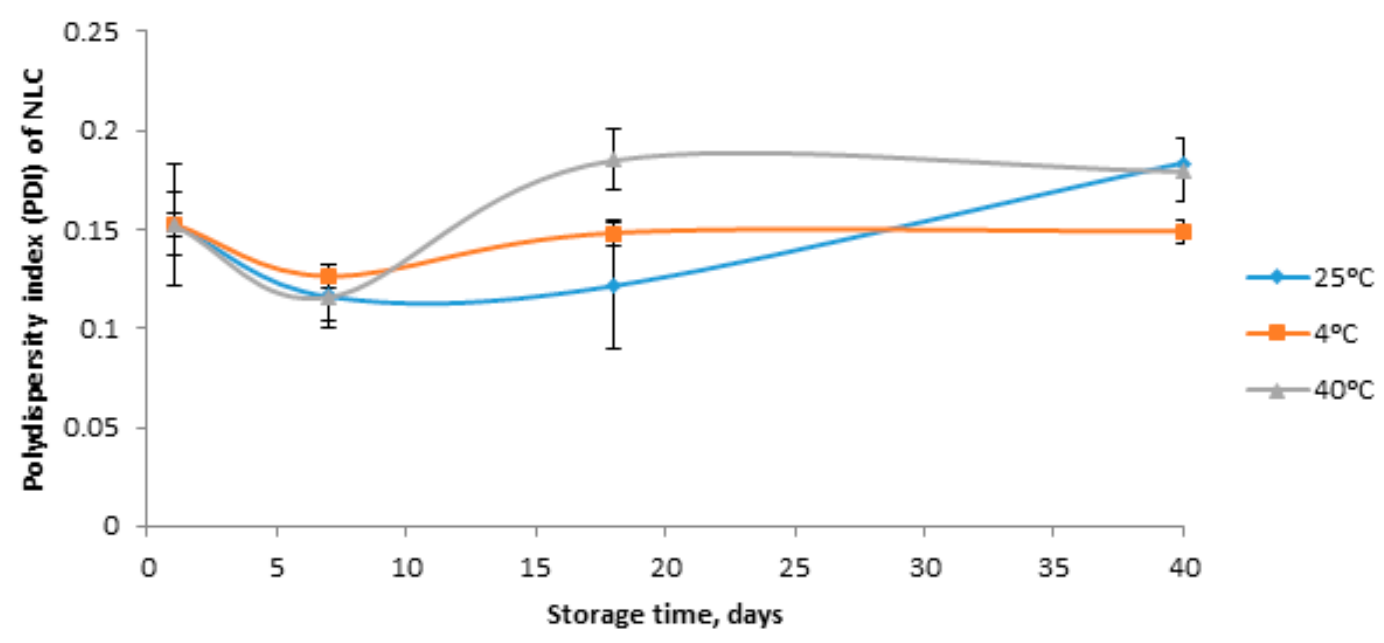

Figure 5. Changes of PDI of FDNLC during storage at $4{ }^{\circ} \mathrm{C}, 25^{\circ} \mathrm{C}$ and $40{ }^{\circ} \mathrm{C}$ throughout 40 days of study. Experiments were done in triplicate $(n=3)$.

\subsection{Antioxidant Activity of FD Loaded Nanostructured Lipid Carrier}

DPPH assay is one of the most preferable antioxidant tests because it is rather simple and has high sensitivity. The effect of antioxidants on DPPH is based on their hydrogen-donating ability. When hydrogen atoms accept an unpaired electron of DPPH from antioxidants, DPPH is reduced to yield DPPH-H, resulting in a change in the absorbance spectrum [33]. The scavenging activity of various concentrations of FDNLC and control (Trolox and ascorbic acid) on DPPH radicals was performed. The ability of FDNLC to reduce DPPH radicals was determined by UV absorbance at $517 \mathrm{~nm}$. Okonogi et al. explained $\mathrm{IC}_{50}$ as the concentration of tested samples needed for scavenging $\mathrm{DPPH}$ radical in the solution by $50 \%$ [34]. The lower the $\mathrm{IC}_{50}$ value, the stronger the antioxidant activity of the sample. The $\mathrm{IC}_{50}$ value is extrapolated from Figure 6. Table 2 shows that FDNLC had higher antioxidant activity as its $\mathrm{IC}_{50}$ value was $45.41 \mu \mathrm{g} / \mathrm{mL}$ compared to the FD extract $(92.2 \mu \mathrm{g} / \mathrm{mL})$, Trolox $(62.9 \mu \mathrm{g} / \mathrm{mL})$ and ascorbic acid $(180.0 \mu \mathrm{g} / \mathrm{mL})$. This implies only $45.41 \mu \mathrm{g} / \mathrm{mL}$ of FDNLC is needed to reduce the DPPH radicals compared to the standards. The high antioxidant activity of the FDNLC might be associated with the components of the FD extract. Moreover, it could be due to the presence of multiple hydroxyl groups in the structure of vitexin and isovitexin, the biomarker for FD extract. However, FDNLC had higher antioxidant activity than the FD extract, which might be due to the increased bioavailability of active in FDNLC. Increased bioavailability maximizes the active ingredient concentration at the site of action within the skin with, ideally, a minimal systemic uptake. This result might also be caused by the presence of VCO in FDNLC dispersions. The polyphenol compound in VCO reduces the DPPH radicals. The total antioxidant activity of the mixtures of polyphenolic compounds is not a simple addition of each polyphenol compound. In this study, usage of VCO as a liquid lipid not only improves the penetration ability of FD but also facilitate in increasing the antioxidant activity. In Figure 6, it was proven that all samples and control did have the free radical scavenging activity. This is because the DPPH inhibition was high at a low concentration of samples and standards. When the concentration of FDNLC increased from 15.625 to $250 \mu \mathrm{g} / \mathrm{mL}$, the scavenging activity also increased. This is due to the higher concentration of FDNLC that contained a larger number of hydroxyl groups, which are related to their hydrogen-donating ability. The results proved that the FDNLC had the highest antioxidant potential compared to the control, which is Trolox and ascorbic acid, and also the FD extract. 


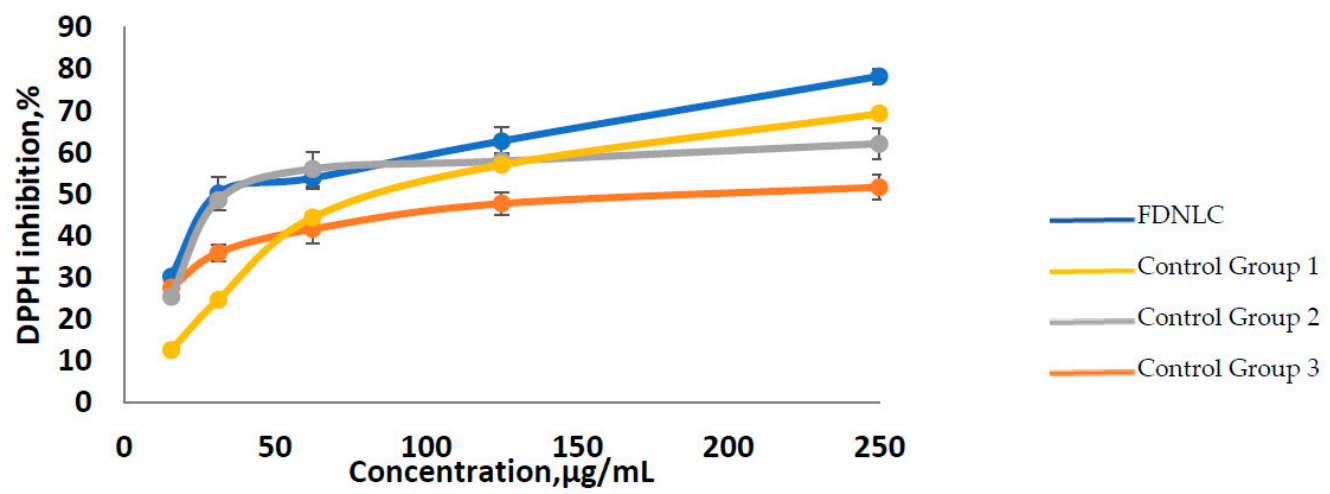

Figure 6. Percentage of DPPH inhibition by FDNLC and standards (Trolox and ascorbic acid). The experiment was done in triplicate $(n=3)$.

Table 2. $\mathrm{IC}_{50}$ value of FDNLC sample, FD extract and standards used in the DPPH assay.

\begin{tabular}{cccc}
\hline Sample/Standard & IC $_{\mathbf{5 0}}$ Value $(\mu \mathrm{g} / \mathbf{m L})$ & Equation & $\boldsymbol{R}^{\mathbf{2}}$ Value \\
\hline FDNLC & 45.41 & $\mathrm{y}=15.694 \ln (\mathrm{x})-9.8861$ & $R^{2}=0.9516$ \\
\hline FD extract & 92.20 & $\mathrm{y}=21.075 \ln (\mathrm{x})-45.628$ & $R^{2}=0.9924$ \\
\hline Trolox & 62.90 & $\mathrm{y}=11.967 \ln (\mathrm{x})+0.4327$ & $R^{2}=0.8024$ \\
\hline Ascorbic acid & 180.00 & $\mathrm{y}=8.6905 \ln (\mathrm{x})+4.8673$ & $R^{2}=0.9845$ \\
\hline
\end{tabular}

\subsection{Skin Permeation}

Penetration studies were conducted using vertical Franz diffusion cells to compare the transportation properties of FDNLC and unencapsulated FD extract. Good transport properties in any delivery system are crucial to transfer the active ingredients into the targeted area. In this study, the Strat-M ${ }^{\mathrm{TM}}$ (Merck Millipore, Billerica, MA, USA) membrane was used as the skin model. This membrane is composed of multiple layers of polyester sulfone, which could be used as an alternative to animal or human skin in permeation studies. The skin permeation study was performed for $24 \mathrm{~h}$. The in vitro release study of the developed NLC and FD extract are portrayed in Figure 7. The results evidenced a first-order kinetic as the drug is delivered at a rate proportional to the concentration gradient driving the transfer of drug movement. A study by Patel et al. found that in vitro release of the active ingredient from the NLC dispersion is biphasic, with the initial burst effect followed by gradual release of the active ingredient [35]. The results showed a similar trend with the FDNLC. The initial burst release might be due to the presence of unentrapped FD in the NLC dispersion. Burst release can be useful to improve the penetration of the active ingredient, while sustained-release supplies the drug over a prolonged period of time. Non-encapsulated FD extract with the same concentration of the encapsulated extract was applied for skin diffusion study to compare the transport properties of encapsulated and non-encapsulated FD water extract. Total phenolic content (TPC) assay, expressed in gallic acid equivalent (GAE)/g dried extract unit, was utilized to determine FD in the collected samples for diffusion study. The vitexin in FD extract in the diffusion samples were undetectable using HPLC because the amount of vitexin was very small. The TPC assay substituted the HPLC method to quantify the FD extract in the diffusion samples instead. The permeation parameters calculated from slopes of permeation profiles are listed in Table 3. Steady-state flux, J is the amount of permeant crossing the skin at a constant rate into the circulating system per unit area. It can be seen from the graph, that the slope of the FDNLC was steeper than the FD extract. FDNLC had higher flux, which was $12.73 \mathrm{mg} / \mathrm{cm}^{2} / \mathrm{h}$ compared to the FD extract, which was only $7.10 \mathrm{mg} / \mathrm{cm}^{2} / \mathrm{h}$. Higher flux indicates a better skin penetration. Permeability coefficient, Kp indicates the rate of permeant penetration per unit concentration expressed in distance/time. Kp for FDNLC was $0.098 \mathrm{~cm} / \mathrm{h}$ 
while for FD extract was only $0.04 \mathrm{~cm} / \mathrm{h}$. The lag phase of FDNLC was only $0.023 \mathrm{~h}$ while for FD extract was $0.223 \mathrm{~h}$. FDNLC showed rapid penetration through the skin with a very short lag period after application, indicating that steady-state permeation was reached quickly. This is because the hydrophilic FD extract had already been encapsulated in the lipid-based carrier. Lag phase increase for the FD extract. This might be due to the hydrophilic nature of the FD extract. This property of FD extract will cause it to face difficulties in penetrating the intercellular part of the stratum corneum because of the difference in polarity.

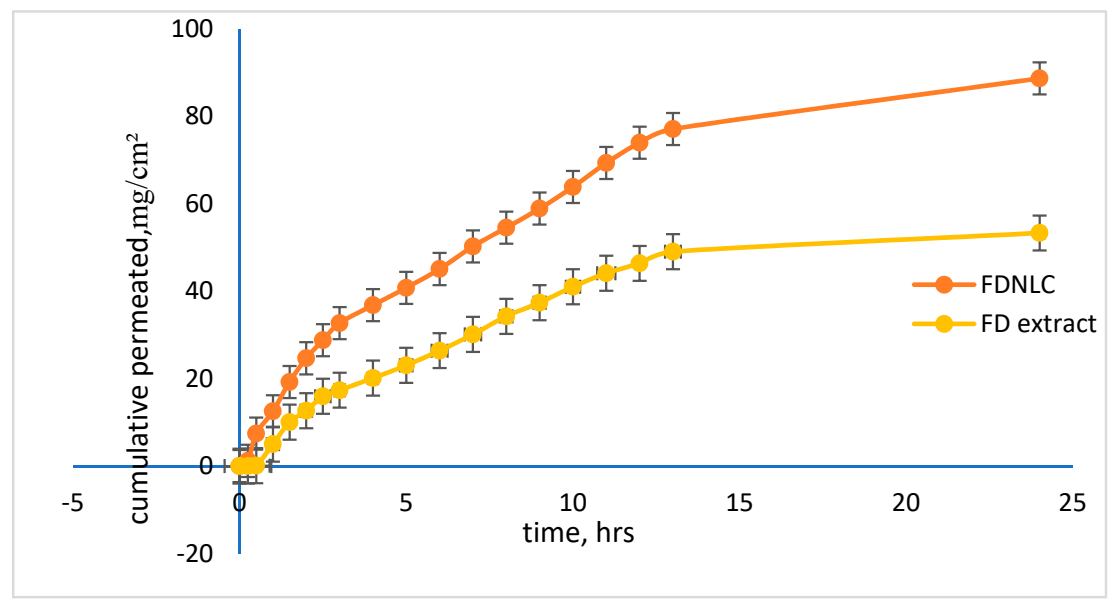

Figure 7. Cumulative amount of FD permeated for $24 \mathrm{~h}$ using Strat-M as the membrane.

Table 3. Permeation parameters for FDNLC and FD extract for the penetration study using Strat-M as the membrane.

\begin{tabular}{|c|c|c|c|}
\hline Samples & $\mathrm{J}(\mathrm{mg} / \mathrm{cm} / \mathrm{h})$ & $\mathrm{Kp}(\mathrm{cm} / \mathrm{h})$ & Tl (hrs) \\
\hline FDNLC & 12.727 & $9.8 \times 10^{-2}$ & 0.023 \\
\hline Unencapsulated FD extract & 7.1004 & $4 \times 10^{-2}$ & 0.223 \\
\hline
\end{tabular}

\subsection{Cell Proliferative Assay}

The MTT (3-[4-dimethylthiazol-2-yl]-2, 5 diphenyl tetrazolium bromide) assay is based on the conversion of MTT into formazan crystals by living cells, which determines their mitochondrial activity. Since, for most cell populations, the total mitochondrial activity correlates to the number of viable cells, this assay is widely utilized to measure the in vitro cytotoxic effects of active compounds on cell lines or primary patient cells. For this study, the result in Figure 8 revealed that both FDNLC and FD extract increased cell growth of the human skin fibroblast (HSF) cell lines. For the normal HSF cell, the cell viability increased with increasing concentration of FDNLC and FD extract. The highest peak was at $100 \mu \mathrm{g} / \mathrm{mL}$ of FDNLC, which demonstrated viability at $150 \% \pm 0.4 \%$. At 50 and $100 \mu \mathrm{g} / \mathrm{mL}$, the cell viability in the occurrence of the FD extract was significantly lower than the cell viability in FDNLC. Figure 8 shows that cell viability increased when the concentration of FD extract was higher. This shows that the compounds in FD are capable of proliferating the normal skin cell. This is supported by the study by Abdulla et al. [4], which shows enhancement in wound healing in rats. The rats treated with FD also showed decreased scar width, more fibroblast proliferation and more collagen fibers accompanied by angiogenesis in the granulation tissue. This might be due to the antioxidant activity and also the phenolic content in the FD itself. However, cell viability was higher in NLC as seen in Figure 8. This might be because NLC has other components such as virgin coconut oil, which also could help in proliferating of the cell, and also NLC is said to increase the efficiency of the active ingredients, which in this study was FD. 


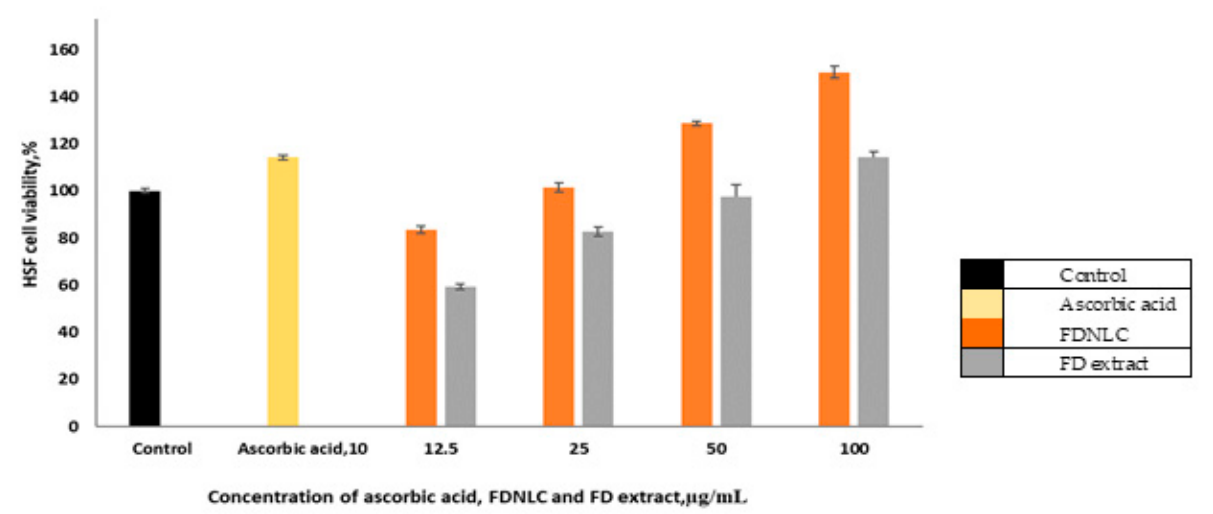

Figure 8. Cell viability of fibroblast cells (HSF 1184) cultured with increasing concentrations of FDNLC using the MTT assay. Data are presented as mean $\pm \operatorname{SD}(n=3)$. Ascorbic acid, 10-ascorbic acid at $10 \mu \mathrm{g} / \mathrm{mL}$ concentration. Control is the cell treated with DMEM only. ${ }^{*} p<0.05$ as compared to FDNLC, indicate a statistically significant value.

UV irradiation is one of the biggest threats to the skin barrier function to perform well. Thus, the HSF cell was treated with induced UVB before treated with FDNLC to prove FDNLC could potentially treat UV irradiation. As for the induced UV irradiation experiment, Figure 9 displays that the cell viability decreased to about $72 \% \pm 1.2 \%$ after being treated with UV irradiation. After treated with ascorbic acid as a positive control, cell viability increased to $76 \% \pm 2.0 \%$. It can also be seen, when the cell was treated with $12.5 \mu \mathrm{g} / \mathrm{mL}$ of FDNLC, the cell viability increased almost similar to when it was treated with ascorbic acid. With $50 \mu \mathrm{g} / \mathrm{mL}$ of FDNLC, cell viability also increased compared to UV treated cells. When using a high concentration of FD extract, cell viability also increased. This concludes that the damage caused by UV irradiation on fibroblast cells can be potentially treated using FDNLC, due to the components such as antioxidant and total phenolic content in the FDNLC that could promote fibroblast cell proliferation. In Figure 9, for the cell viability with treatment of the FD extract (after $12.5 \mu \mathrm{g} / \mathrm{mL}$ ), UV irradiation was only $45 \%$ and might be because the concentration was not enough to treat the UV induced cell. The UV irradiated cell was an abnormal cell, which might be harder to treat with a low concentration of FD extract only. A study by [36] has shown the aqueous extracts of four varieties of FD were not toxic within the tested concentration range from 1 to $1 \mathrm{mg} / \mathrm{mL}$. However, it is not totally denied that the FD extract might have its own toxicity.

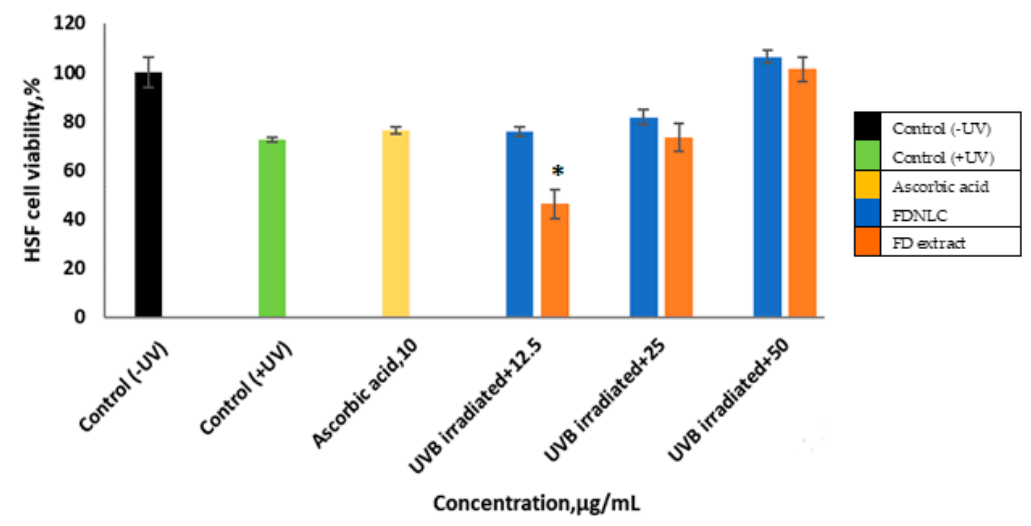

Figure 9. The effect of FDNLC on cell viability of fibroblast cells (HSF 1184) after UVB (ultraviolet B) irradiation $\left(15.0 \mathrm{~mJ} / \mathrm{cm}^{2}, 320 \mathrm{~nm}\right)$. Data are presented as mean $\pm \mathrm{SD}(n=3)$. Ascorbic acid, 10-ascorbic acid at $10 \mu \mathrm{g} / \mathrm{mL}$ concentration. ${ }^{*} p<0.05$ as compared to FDNLC, indicate a statistically significant value. 


\section{Conclusions}

For the formulation of the nanostructured lipid carrier loaded with Ficus deltoidea extract (FDNLC) with the desired particle size, the polydispersity index (PDI) was successfully obtained. The study showed encapsulation efficiency and active ingredient loading capacity for FDNLC was $87.4 \% \pm 1.3 \%$ and $8.5 \% \pm 1.2 \%$, respectively, and was stable for at least 40 days. Antioxidant activity of FDNLC was highest when compared to Ficus deltoidea extract and standards. Results from cell cytotoxicity study proved that FDNLC was not toxic to normal skin cells, and damage by Ultraviolet B (UVB) irradiation could potentially be treated by FDNLC. Taking the findings from the study, FDNLC could be a potential topical treatment for skin issues. Further research on the FDNLC ability on treating skin issues should be done to support this study.

Author Contributions: Conceptualization, Research design, R.H.; Conduct the experiment and writing the manuscript, N.A.N.A.; writing-review and editing, R.H., A.A.M.E. and H.M.S.; supervision, R.H.; project administration, F.D.A.; funding acquisition, R.H. All authors have read and agreed to the published version of the manuscript.

Funding: This research was funded by the Ministry of Education Malaysia, Prototype Research Grant Scheme (R.J13000.7846.4L656), HiCoE (RJ13000.7856.4J266) and Fundamental Research Grant Scheme (RJ1300.7809.4F614).

Conflicts of Interest: The authors declare no conflict of interest.

\section{References}

1. Bunawan, H.; Amin, N.M.; Bunawan, S.N.; Baharum, S.N.; Mohd Noor, N. Ficus deltoidea jack: A review on its phytochemical and pharmacological importance. Evid. Based Complement. Altern. Med. 2014, 2014, 1-8. [CrossRef] [PubMed]

2. Haron, S.H. Enzymatic Extraction of Ficus deltoidea for Better Enhancement of Extracted Yield. Bachelor's Thesis, University Putra Malaysia, Seri Kembangan, Malaysia, 2014.

3. Hasham, R.; Choi, H.K.; Sarmidi, M.R.; Park, C.S. Protective effects of a Ficus deltoidea (Mas cotek) extract against UVB-induced photoageing in skin cells. Biotechnol. Bioprocess Eng. 2013, 18, 185-193. [CrossRef]

4. Abdulla, M.A.; Ahmed, K.A.-A.; Abu-Luhoom, F.M.; Muhanid, M. Role of Ficus deltoidea extract in the enhancement of wound healing in experimental rats. Biomed. Res. 2010, 21, 241-245.

5. Vinardell, M.P.; Mitjans, M. Nanocarriers for Delivery of Antioxidants on the Skin. Cosmetics 2015, 2, 342-354. [CrossRef]

6. Desai, P.; Patlolla, R.R.; Singh, M. Interaction of nanoparticles and cell-penetrating peptides with skin for transdermal drug delivery. Mol. Membr. Biol. 2010, 27, 247-259. [CrossRef] [PubMed]

7. Müller, R.H.; Radtke, M.; Wissing, S.A. Solid lipid nanoparticles (SLN) and nanostructured lipid carriers (NLC) in cosmetic and dermatological preparations. Adv. Drug Deliv. Rev. 2002, 54 (Suppl. S1), S131-S155.

8. Pardeshi, C.; Rajput, P.; Belgamwar, V.; Tekade, A.; Patil, G.; Chaudhary, K.; Sonje, A. Solid lipid based nanocarriers: An overview. Acta Pharm. 2012, 62, 433-472. [CrossRef]

9. Lacatusu, I.; Niculae, G.; Badea, N.; Stan, R.; Popa, O.; Oprea, O.; Meghea, A. Design of soft lipid nanocarriers based on bioactive vegetable oils with multiple health benefits. Chem. Eng. J. 2014, 246, 311-321. [CrossRef]

10. Tichota, D.M.; Silva, A.C.; Sousa Lobo, J.M.; Amaral, M.H. Design, characterization, and clinical evaluation of argan oil nanostructured lipid carriers to improve skin hydration. Int. J. Nanomed. 2014, 9, 3855-3864.

11. Li, B.; Ge, Z.Q. Nanostructured lipid carriers improve skin permeation and chemical stability of idebenone. AAPS PharmSciTech 2012, 13, 276-283. [CrossRef]

12. Müller, R.H.; Petersen, R.D.; Hommoss, A.; Pardeike, J. Nanostructured lipid carriers (NLC) in cosmetic dermal products. Adv. Drug Deliv. Rev. 2007, 59, 522-530. [CrossRef] [PubMed]

13. Mansor, T.S.T.; Che Man, Y.B.; Shuhaimi, M.; Abdul Afiq, M.J.; Ku Nurul, F.K.M. Physicochemical properties of virgin coconut oil extracted from different processing methods. Int. Food Res. J. 2012, 19, 837-845.

14. Marina, A.M.; Che Man, Y.B.; Nazimah, S.A.H.; Amin, I. Chemical Properties of Virgin Coconut Oil. J. Am. Oil Chem. Soc. 2009, 86, 301-307. [CrossRef]

15. Rohman, A.; Man, Y.C. Sismindari Quantitative analysis of virgin coconut oil in cream cosmetics preparations using fourier transform infrared (FTIR) spectroscopy. Pak. J. Pharm. Sci. 2009, 22, 415-420. [PubMed] 
16. Kim, S.; Jang, J.E.; Kim, J.; Lee, Y.I.; Lee, D.W.; Song, S.Y.; Lee, J.H. Enhanced barrier functions and anti-inflammatory effect of cultured coconut extract on human skin. Food Chem. Toxicol. 2017, 106, 367-375. [CrossRef]

17. Rosli, N.A.; Hasham, R.; Aziz, A. Design and physicochemical evaluation of lipid encapsulated Zingiber Zerumbut Oil by D-optimal mixture design. J. Teknol. 2018, 3, 105-113.

18. Uprit, S.; Kumar Sahu, R.; Roy, A.; Pare, A. Preparation and characterization of minoxidil loaded nanostructured lipid carrier gel for effective treatment of alopecia. Saudi Pharm. J. 2013, 21, 379-385. [CrossRef]

19. Dangi, R.S.; Shakya, S. Preparation, optimization and characterization of PLGA nanoparticle. Int. J. Pharm. Life Sci. 2013, 4, 2810-2818.

20. Noor, N.M.; Khan, A.A.; Hasham, R.; Talib, A.; Sarmidi, M.R.; Aziz, R.; Abd, A. Empty nano and micro-structured lipid carriers of virgin coconut oil for skin moisturisation. IET Nanobiotechnol. 2016, 10, 195-199. [CrossRef]

21. Sharma, O.P.; Bhat, T.K. DPPH antioxidant assay revisited. Food Chem. 2009, 113, 1202-1205. [CrossRef]

22. Azlim Almey, A.J.K.S.Z.S. Total phenolic content and primary antioxidant activity of methanolic and ethanolic extracts of aromatic plants' leafs. Int. Food Res. J. 2010, 17, 1077-1084.

23. Da Costa, S.; Basri, M.; Shamsudin, N.; Basri, H. Stability of Positively Charged Nanoemulsion Formulation Containing Steroidal Drug for Effective Transdermal Application. J. Chem. 2014, 2014, 1-8. [CrossRef]

24. Zirak, M.B.; Pezeshki, A. Effect of Surfactant Concentration on the Particle Size, Stability and Potential Zeta of Beta carotene Nano Lipid Carrier. Int. J. Curr. Microbiol. Appl. Sci. 2015, 4, 924-932.

25. Das, S.; Ng, W.K.; Kanaujia, P.; Kim, S.; Tan, R.B.H. Formulation design, preparation and physicochemical characterizations of solid lipid nanoparticles containing a hydrophobic drug: Effects of process variables. Colloids Surfaces B Biointerfaces 2011, 88, 483-489. [CrossRef]

26. Mitri, K.; Shegokar, R.; Gohla, S.; Anselmi, C.; Müller, R.H. Lipid nanocarriers for dermal delivery of lutein: Preparation, characterization, stability and performance. Int. J. Pharm. 2011, 414, 267-275. [CrossRef] [PubMed]

27. Gonzalez-Mira, E.; Egea, M.A.; Garcia, M.L.; Souto, E.B. Design and ocular tolerance of flurbiprofen loaded ultrasound-engineered NLC. Colloids Surfaces B Biointerfaces 2010, 81, 412-421. [CrossRef]

28. Jia, L.J.; Zhang, D.R.; Li, Z.Y.; Feng, F.F.; Wang, Y.C.; Dai, W.T.; Duan, C.X.; Zhang, Q. Preparation and characterization of silybin-loaded nanostructured lipid carriers. Drug Deliv. 2010, 17, 11-18. [CrossRef] [PubMed]

29. Chu, B.; Zhang, L.; Qu, Y.; Chen, X.; Peng, J.; Huang, Y.; Qian, Z. Synthesis, characterization and drug loading property of monomethoxy-poly(ethylene glycol)-poly( $\epsilon$-caprolactone)-poly(D,L-lactide) (MPEG-PCLA) copolymers. Sci. Rep. 2016, 6, 1-15. [CrossRef]

30. Jenning, V.; Thünemann, A.F.; Gohla, S.H. Characterisation of a novel solid lipid nanoparticle carrier system based on binary mixtures of liquid and solid lipids. Int. J. Pharm. 2000, 199, 167-177. [CrossRef]

31. Venkateswarlu, V.; Manjunath, K. Preparation, characterization and in vitro release kinetics of clozapine solid lipid nanoparticles. J. Control. Release 2004, 95, 627-638. [CrossRef]

32. Huang, J.; Wang, Q.; Li, T.; Xia, N.; Xia, Q. Nanostructured lipid carrier (NLC) as a strategy for encapsulation of quercetin and linseed oil: Preparation and in vitro characterization studies. J. Food Eng. 2017, 215, 1-12. [CrossRef]

33. Antolovich, M.; Prenzler, P.D.; Patsalides, E.; McDonald, S.; Robards, K. Methods for testing antioxidant activity. Analyst 2002, 127, 183-198. [CrossRef] [PubMed]

34. Okonogi, S.; Duangrat, C.; Anuchpreeda, S.; Tachakittirungrod, S.; Chowwanapoonpohn, S. Comparison of antioxidant capacities and cytotoxicities of certain fruit peels. Food Chem. 2007, 103, 839-846. [CrossRef]

35. Mishra, B.; Patel, B.B.; Tiwari, S. Colloidal nanocarriers: A review on formulation technology, types and applications toward targeted drug delivery. Nanomed. Nanotechnol. Biol. Med. 2010, 6, 9-24. [CrossRef] [PubMed]

36. Dzolin, S.; Sharipah Ruzaina Syed Aris; Ahmad, R.; Zain, M.M. Radical scavenging and neurotoxicity of four varieties of Ficus deltoidea. In Proceedings of the CSSR 2010-2010 International Conference on Science and Social Research, Kuala Lumpur, Malaysia, 5-7 December 2010; pp. 11-15.

Publisher's Note: MDPI stays neutral with regard to jurisdictional claims in published maps and institutional affiliations. 